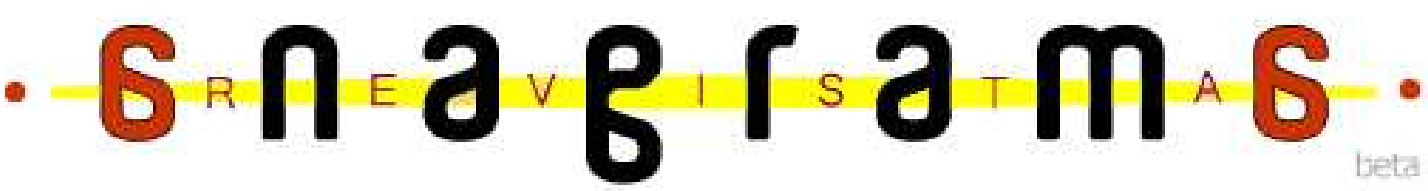

Atos Secretos do Senado:

\section{uma análise do enquadramento de Sarney no jornalismo do CQC}

\author{
Gabriel Lautenschleger'
}

\section{Resumo}

As análises e apresentações sobre enquadramento nos programas jornalísticos, principalmente na televisão brasileira são bastante carentes na questão de assuntos trabalhados. O campo televisivo é muito amplo e pouco trabalhado em questões que trazem a luz análises de agendamento e enquadramento midiático, a televisão é estudada basicamente em assuntos referentes à análise de conteúdo e estudos de recepção, mas não em vista das Teorias do Jornalismo. O presente artigo pretende um estudo do novato programa Custe o Que Custar (CQC) e o enquadramento dado por esse programa do novo jornalismo ao caso de Atos Secretos praticados no Senado Nacional pelo Senador José Sarney.

Palauras-chave: Teorias do Jornalismo; Humor Jornalístico; Enquadramento; Política.

\section{Considerações Iniciais}

Os estudos de enquadramento midiático não são muito desenvolvidos no país, em vista do trabalho de análise de enquadramento ser delicada. É complicado analisar um programa e descobrir sua postura perante algum assunto, alguma pessoa ou personalidade do mundo, seja ela: do mundo da moda, da música, ou até mesmo um político.

As análises buscam a postura pela linguagem, gestos, tom de voz e até no caso de revistas ou jornais pelas fotos, posição de destaque, cores, enfim por detalhes que em muitas vezes não nos prendemos em analisar ou observar, pensando assim na transparência do meio ao qual estamos nos informando.

\footnotetext{
${ }^{1}$ Acadêmico do sexto semestre do curso de Jornalismo da Universidade Federal de Santa Maria - Campus de Frederico Westphalen. Endereço eletrônico: gabriel.jornal@mail.ufsm.br
} 
As pessoas apenas enxergam o mundo através de uma moldura de uma janela. Se a moldura da janela é muito pequena, as pessoas já enxergarão uma pequena parte do mundo. Se a janela na parede é voltada para o oeste, as pessoas apenas enxergarão o oeste. Em outras palavras, a mídia pode mostrar apenas uma pequena parte do mundo a partir de um particular ponto de vista. (PARK, 2003, p.145 apud LEAL, 2007, p. 1)

O cuidado ao efetuar a análise aos assuntos é muito grande, devido ao fato de não nos deixarmos levar pela imaginação, em muitas vezes as informações estão "maquiadas" de tal forma que só com uma análise muito dedicada o enquadramento do programa ou jornal pode ser visto.

Estudos em televisão são feitos em baixa escala aqui, os principais só abordam uma análise breve de conteúdo, mais ligados a temas de sociologia, cultura e pouco relacionados à essência real do jornalismo teórico, análises da maneira de abordagem do conteúdo, a maneira que os meios de comunicação de massa pautam assuntos que serão discutidos no decorrer de um dia, no caso de jornal diário, ou na semana no caso de programas ou jornais semanais.

O programa CQC apresentado semanalmente na rede Bandeirantes de Comunicação é um programa de cunho telejornalístico, pautado em aspectos de humor, mas considerado um novo modelo de telejornalismo no país, traz aspectos dos telejornais tradicionais partindo pela posição dos apresentadores, assentados em uma bancada, simulando um telejornal tradicional. A desconstrução da linguagem telejornalistica tradicional é um ponto do $C Q C$. O plano editorial do programa traz para a "telinha" as principais informações, notícias e fatos da semana de uma maneira em que o humor vem a ser o ponto chave da programação. A linguagem, dos recursos, valores e de termos da retórica do jornalismo, são estratégias de construção editorial do programa, que tem a sua construção com pauta nos recursos jornalísticos tradicionais incrementados pela estética do humor televisivo.

O Senado Federal, e principalmente a família Sarney, tem uma longa trajetória de murmúrios e escândalos sobre Nepotismo ${ }^{2}$ e Favorecimento ${ }^{3}$, no que diz respeito a cargos de confiança e nomeações por meio de atos secretos que são considerados crimes em vista de que qualquer órgão público deve tornar públicas todas suas ações pelo Diário Oficial da

\footnotetext{
${ }^{2}$ Nepotismo é o termo utilizado para designar o favorecimento de parentes em detrimento de pessoas mais qualificadas, especialmente no que diz respeito à nomeação ou elevação de cargos.

${ }_{3}^{3}$ Favorecimento difere-se de Nepotismo no que diz respeito a parentes de qualquer grau, o favorecimento não necessita grau de parentesco.
} 
União e pelos meios de comunicação, para que a maior parcela da população tenha acesso ao que tramita no Congresso e nos gabinetes dos parlamentares.

A análise de enquadramento que será realizada com base no programa jornalístico $C Q C$ tem como objetivo a busca pela postura e o porquê dessa linha editorial que o programa emprega quando noticia informações sobre os escândalos dos Atos Secretos praticados dentro do Senado pelo Senador e então presidente da Casa José Sarney e sua família.

\section{Enquadramento Midiático}

O enquadramento midiático se baseia na principal questão: Como é trabalhada determinada informação? Os estudos em enquadramento são baseados principalmente em selecionar e deixar mais salientes em evidência determinados assuntos da realidade abordados nos diferentes meios.

Esta perspectiva está relacionada diretamente com revisões recentes da teoria de agendasetting, mais em concreto com a denominada teoria da "segunda dimensão". Esta nova abordagem nos diz que os meios constroem a agenda através de dois mecanismos: dizendo sobre que assuntos temos que pensar (primeiro nível) e como devemos pensar nesses assuntos (segundo nível); (MACIEL; SABBATINI, 2005, p. 5)

Enquadramentos são de certa forma elementos que são cognitivos estruturam a seleção do que é mais saliente, o que é mais importante na realidade e o que merece ou não ser transformado em notícia, qual é o interesse público, o que realmente importa na informação e de que maneira essa informação deve ser passada ao público.

O que é publicado, o que não se publica, o importante, o essencial, o inédito, tudo é uma escolha, e essas escolhas que montam o enquadramento midiático, definido pelo jornalista ou editor.

Enquadramentos noticiosos como padrões persistentes de cognição, interpretação, apresentação, seleção, ênfase e exclusão, através dos quais aqueles que trabalham os símbolos, organizam tanto o discurso verbal como discurso visual. É possível efetuar a abordagem quantitativa sobre os processos de enquadramento simbólico, procurando as palavras a chave e a linguagem comum que nos permitem identificar um frame (GITLIN, 1980, P. 7 apud CORREIA, 2009)

No campo de análise do enquadramento podem ser avaliadas várias perspectivas para chegar ao resultado da pesquisa, destaques no título, fotos, e outros detalhes revelam a 
maneira que os editores e repórteres tentaram mostrar o que eles realmente queriam que fosse visualizado pelo público, trazendo assim a sua própria linha editorial intrínseca no conteúdo da sua matéria, seja ela televisiva, impressa, online ou radiofônica.

Entre os elementos que, no plano simbólico e discursivo, na pesquisa sobre um determinado texto, para identificar um enquadramento, podem ser analisados destaquem-se: a) manchetes e títulos; b) subtítulos; c) fotografias d) legendas fotográficas; d) leads; e) seleção das fontes; f) citações selecionadas; g) realce das citações; h) identificação gráfica dos artigos caso seja feita uma série sobre um tema; i) estatísticas e gráficos; j) parágrafos conclusivos (JAMES TANKARD. JR 2001, p. 101 apud CORREIA, 2009)

O tratamento que se dá aos acontecimentos é o seguinte passo que devemos ter em conta. Neste sentido, nos encontramos com a teoria do enquadramento entendido como o processo pelo qual os meios de comunicação enquadram os acontecimentos sociais: (a) selecionando alguns aspectos de uma realidade percebida, que recebendo maior relevância em uma mensagem, destaca-as; (b) uma definição concreta, (c) uma interpretação causal; (d) um juízo moral e/ou (e) uma recomendação para seu tratamento (ENTMAN, 1993).

Os estudos de comunicação científica proposta por Väliverronen (1998) destaca o referencial teórico por ele analisado e estudado, abordando a existência e identificando cinco enquadramentos midiáticos, sendo eles representados da seguinte forma:

a) "Divulgação": tem o sentido de divulgar e explanar conhecimentos científicos e de natureza tecnológica, informações sobre tecnologias e novas tecnologias.

b) "Impacto Social": Ressalta principalmente assuntos que se referem a repercussões (reais) de caráter tanto positivo, como material de natureza negativa.

c) "Política científica": Situa-se principalmente com base em material de cunho político trazendo as questões a um quadro mais amplo sempre contrapondo com relações de política científica ou assuntos jurídicos.

d) "Legitimação/deslegitimação da ciência": contrapontos, enquadramentos opostos pautando o debate da validez da ciência, mostrando assim seu Status de honra, ou do contrário suas falhas e contradições.

e) "Outro": assuntos, textos, matérias que não se encaixam em algum dos outros quatro enquadramentos, pautados não em Tecnológico, Impacto Social, Política e Ciência, enfim, todos os assuntos referentes a outras causas. 
Mesmo o enquadramento sendo muito utilizado nos estudos de comunicação, o mesmo vem sofrendo algumas observações críticas quanto ao seu entendimento, como Koenig (2004) afirma que as análises hoje realizadas nada mais têm do conceito de enquadramento criado por Goffman. Porto (2002) concorda com a idéia explanada por Koenig e propõe que o problema está nos usos diferentes e controversos do próprio conceito:

Apesar do seu uso crescente nos estudos sobre processos de comunicação, as primeiras revisões sistemáticas da literatura sobre enquadramento sugerem que ainda existe uma falta de clareza nos diversos usos do conceito e que muito precisa ser feito para se desenvolver uma teoria abrangente e coerente. (PORTO, 2002).

Fisher no seu Artigo: 'Locating Frames in the Discursive Universe' reafirma alguns pontos estudados por Goffman, que é considerado o precursor no estudo do Enquadramento:

Em 1974, Erving Goffman propôs uma nova dimensão de sua metodologia sóciosemiológica para estudar as imagens visuais e as representações culturais que denominou 'análise de enquadramento'. Seus textos sobre enquadramento não estavam entre os seus melhores, e Goffman não investiu mais tanto esforço em desenvolver o conceito da moldação como fez a outros aspectos de estudar o significado, a representação, e as imagens. Porém este texto particular serviu para inflamar uma corrente da literatura da análise do frame (FISCHER, 2007, tradução nossa) ${ }^{4}$.

Sendo citado como o pai da teoria, afirmando que a teoria do enquadramento quando estudada por Goffman, foi analisada de dois quadros distintos:

Nas análises de enquadramento, Goffman discutiu que as culturas geram enquadramentos preliminares, que rendem 'o que seria de certa maneira um aspecto sem sentido da cena' sendo um ponto de comparação, ou uma estrutura conceitual, através de que os povos podem digerir a informação (Goffman, 1974: p. 21). Goffman sugeriu que cada cultura produzisse dois tipos de estruturas preliminares: enquadramentos naturais e enquadramentos sociais (FISHER, 2007, tradução nossa) ${ }^{5}$

\footnotetext{
${ }^{4}$ In 1974, Erving Goffman proposed a new dimension of his socio-semiological methodology for studying visual images and cultural representations which he termed 'frame analysis'. His text of the same name was not among his better received, and Goffman did not later invest as much effort into developing the concept of framing as he did to other aspects of studying meaning, representation, and images. As this particular text nonetheless served to ignite one branch of the frame analysis literature, it is useful to begin by examining the arguments within it.

5 In Frame Analysis, Goffman argued that cultures generate 'primary frameworks', which render 'what would otherwise be a meaningless aspect of the scene into something that is meaningful' by offering a point of comparison, or a conceptual structure, through which people can digest information (Goffman, 1974: p. 21).
} 


\section{Um nouo Conceito de Jornalismo}

A partir de meados de 2000, a televisão brasileira passou a conceder mais espaço a programas que trabalham de uma maneira diferente o jornalismo, trazendo para a telinha informações e notícias que interessam o público, mas com uma "pitadinha" de humor. O $C Q C$ se considera um programa jornalístico, mesmo trazendo humor nas suas reportagens e matérias dos principais acontecimentos da semana.

Em entrevista à revista Playboy, em sua edição de janeiro de 2009, o apresentador Marcelo Tas é enfático, reiterando que o $C Q C$ “'́́ jornalismo. Agora é, um jornalismo feito com humor. A gente é jornalista que faz humor profissional. Acho que aí está a diferença" (2009, p. 40)

Esse jornalismo com humor tem alcançado altos índices de audiência para a Rede Bandeirantes, subindo da média de 2,6 pontos obtidos em anos anteriores para os atuais 8 pontos. O que não deixa de ser um feito, ainda mais considerando a quantidade de atrações de outras emissoras disputando a audiência no mesmo horário.

\section{Um Breve Relato do Caso Sarney}

Os escândalos da família Sarney são há certo tempo pautados nos nossos meios de comunicação, não apenas aqui no Brasil, mas escândalos mencionados em meios de comunicação estrangeiros, trazendo até um certo tipo de vergonha para o Brasil, mostrando impunidade para os que detém o poder no país.

Um dos casos mais comentados que rondaram o Congresso Nacional, foi a contratação do neto do presidente do senado senador José Sarney, João Fernando Michels Gonçalves Sarney para o gabinete do senador Epitácio Cafeteira o que configura Nepotismo Cruzado ${ }^{7}$. A justiça grampeou ligações para que os escândalos pudessem ser descobertos e consequentemente os envolvidos punidos, no entanto o neto foi demitido e logo após, a mãe de João Fernando ocupou seu lugar no Gabinete do senador Cafeteira, com o mesmo salário que o estudante recebia mesmo sem ter concluído a graduação, R\$ 7,6 mil.

Goffman suggested that each culture produces two types of primary frameworks: natural frameworks and social frameworks.

${ }^{6}$ Grifos nossos.

${ }^{7} \mathrm{O}$ nepotismo cruzado ocorre quando um agente público emprega o familiar do outro e vice-versa como troca de favores políticos, ou pessoais. 


\section{O CQC e os Casos Sarney e Senado}

Não é recente que o programa $C Q C$ da Rede Bandeirantes caracterize muita cobrança e abordagem bem ampla de assuntos políticos, principalmente escândalos que são coisas mais frequentes no Congresso Nacional. O repórter Danilo Gentilli visitou o congresso nacional e realizou uma matéria veiculada no CQC do dia 22 de Junho de 2009.

Os repórteres do $C Q C$ sempre aparecem com ternos e microfones na mão, procurando obter com a sua imagem um maior 'status' de credibilidade, o que de certa forma acontece.

Na matéria veiculada no dia 22 de junho, o repórter aparece na frente da Praça dos Três Poderes em Brasília, e começa a explanação do assunto: "A principal instituição da nossa democracia, vem sofrendo a algum tempo uma série de ataques...", no momento seguinte é feita uma sátira aos ataques de 11 de setembro de 2001, mostrando uma mosca gigante acertando as Torres do Congresso, demonstrando assim já um certo sarcasmo sobre os escândalos de Nepotismo. Um ponto a ser explanado foi o fato de o repórter fazer sinais de aspas com os dedos quando fala que para a direção do senado o problema de nepotismo do senador Sarney foram problemas técnicos.

Na sequência o repórter já se encontra dentro do prédio que abriga o senado e procura entrar em contado para conversar com alguns senadores observa-se nesses momentos, que a busca é por senadores que já são reconhecidos por quase todos no país, senadores que já estiveram envolvidos de alguma maneira com corrupção, sejam eles julgando ou praticando. Os escolhidos são aliados do Senador Sarney, integrantes do seu partido, ou aliados ao presidente Lula.

Em conversa com o Senador Aloísio Mercadante, Danilo Gentilli faz algumas afirmações sobre a conduta do presidente Lula, quanto ao senador Sarney, explicando:

\footnotetext{
"Não muito atrás o Lula criticava o Sarney e agora ele elogia, dizendo que Sarney tem uma trajetória respeitável, será que ele mudou a visão ou tem um certo interesse aí por causa da CPI da Petrobrás, pra abafar os casos".
}

Nessa citação do repórter, pode-se observar uma crítica, algo ameaçador sobre o presidente Lula, ou seja, nesse caso demonstrando, até para o próprio aliado do presidente uma certa indisposição ao governo do presidente Lula e seus aliados. 
Seguindo a matéria, Danilo observa aliados do senador Sarney como Calheiros entre outros em uma reunião em uma pequena sala de vidro, no momento ele explana: “Será que estão planejando os próximos atos secretos?”, fazendo uma crítica à contratação do neto de Sarney, o real motivo da matéria investigativa. Caminhando pelo senado tentando entrevistas com outros senadores, o repórter consegue conversar com o Senador Artur Virgílio da bancada de oposição a Sarney, perguntado sobre os casos de nepotismo ele observa que todos os contratados por parentes devem ser demitidos dos cargos, nesse momento, vem mais uma crítica do $C Q C$ ao país, Danilo fala: "Mas numa época de desemprego demitir os parentes?", aqui acontece o que se diz criticar outro problema se baseando em um problema específico, o desemprego como crítica aos cargos de nepotismo.

A próxima tentativa de entrevista é com o senador responsável pelo gabinete que o neto de Sarney trabalhava. Sem dar muito ouvidos ao que o repórter diz, o senador Epitácio Cafeteira quase o atropela com uma cadeira de rodas, correndo para longe do repórter, mas Danilo corre atrás e faz as criticas sobre o neto de Sarney, dizendo que em tempos de crise o senador ajuda um estudante que não saiu da faculdade com um salário de $\mathrm{R}$ \$ 7,6 mil, criticando assim o senador que não dá muito ouvido.

Eles tentaram contato com o próprio Sarney, mas não sem sucesso, devido a outros casos em que Danilo foi agredido por seguranças de Sarney.

Em entrevista a Playboy na edição de janeiro de 2009, Marcelo Tas conta que os políticos não gostam deles, por que muitas perguntas que os outros jornais não fazem o $C Q C$ faz, perguntas que muitas vezes eles não gostariam de responder levando a uma certa raiva dos repórteres do programa.

\section{Considerações Finais}

Um aspecto que vale a pena trabalhar e isolar para estudos mais aprofundados dentro dos estudos linguísticos e teorias do jornalismo é o estudo da teoria do enquadramento ou framing.

Mesmo com poucos estudos na área do enquadramento televisivo, a trabalho tentou abordar e destacar os principais pontos que são observados pelos autores que trabalham o enquadramento e tentar bases em trabalhos já publicados nas outras áreas da comunicação, seja em impressos, radiofônicos, ou mídia online. 
Podemos observar que os autores que estudam enquadramento encontraram enquadramentos de vários tipos, o que representa que todos os assuntos pautados em meios de comunicação tanto no país como no mundo podem sem analisados com base nos estudos da teoria do enquadramento também conhecida por frame.

A análise do enquadramento, ou teoria do enquadramento, tem uma aproximação muito grande da Agenda Setting ou Teoria do Agendamento que configura interligações entre as teorias do Jornalismo.

No campo de análise do enquadramento são observadas e avaliadas várias perspectivas para chegar ao resultado da pesquisa, destaques no título, fotos, localização das matérias, posição do repórter e postura, movimentos da cabeça e mãos entre outros detalhes que revelam a visão adotada pelos meios de comunicação na definição das suas matérias para o que vira notícia, o que é aproveitado e o que se despreza.

O enquadramento dos casos de atos secretos e nepotismo no senado federal é sim de natureza crítica ao poder público, bem como revela uma crítica em especial ao presidente Lula, mostrando que o presidente em muitas vezes "muda de lado" para obtenção de benefícios políticos.

O caso Sarney em específico representa certas críticas e demonstrações de certa reprovação pelos jornalistas do $C Q C$, o que vale lembrar que todos eles são formados em Comunicação Social com Habilitação em Jornalismo.

\section{Referências Bibliográficas}

CORREIA, João Carlos Ferreira. Os estudos de enquadramento. Março de 2009. Disponível em: http://teoriadanoticia.blogspot.com/2009/03/os-estudos-deenquadramento.html

Fisher, K. (1997) 'Locating Frames in the Discursive Universe' Sociological Research Online, vol. 2, no. 3, Disponível em: http://www.socresonline.org.uk/socresonline/2/3/4.html

GOFFMAN, Erving. Frame Analysis: An Essay on the Organization of Experience. London: Harper and Row. 1974. 
LEAL, Plínio Marcos Volponi. Jornalismo Político Brasileiro e a Análise do Enquadramento Noticioso. Disponível em: www.fafich.ufmg.br/compolitica/anais2007/sc_jp-plinio.pdf, acesso em 04 de janeiro de 2010 .

LOPEZ, Debora Cristina. Agenda setting e enquadramento: algumas considerações sobre os estudos de efeitos dos meios de comunicação. Disponível em: http://www.eca.usp.br/pjbr/arquivos/artigos11_a.html

MACIEL, Betania. SABBATINI Marcelo. Construção da realidade social, meios de comunicação e jornalismo científico na era da tecnociência: uma reflexão. 2005. Disponível em: www.ufrgs.br/gtjornalismocompos/doc2005/betaniamaciel2005.rtf. Acesso em 28 de dezembro de 2009.

Revista Playboy, nº 404. Editora Abril, São Paulo, jan. 2009. 